\title{
EL BLOG COLECTIVO COMO PORTAL DE UN ESPACIO DE AFINIDAD: DESARROLLANDO EL AULA HÍBRIDA EN UNA CLASE UNIVERSITARIA EN COLOMBIA
}

\author{
ANDRÉS LOMBANA-BERMUdEZ* \\ Pontificia Universidad Javeriana \\ andresa.lombana@javeriana.edu.co
}

Recibido: 18/6/2021 Aceptado: 24/8/2021

doi: https://doi.org/10.26439/contratexto2021.n036.5232

RESUMEN. El artículo presenta un estudio de caso sobre una experiencia de aula híbrida desarrollada en una clase universitaria de Comunicación Social en Colombia, en la que se construyó un espacio de afinidad por medio del uso de tecnologías de la información y la comunicación (TIC). Utilizando las teorías de espacio de afinidad (Gee, 2003, 2005, 2017) y aprendizaje conectado (Ito et al., 2013), y con base en datos cualitativos recolectados durante cuatro iteraciones de la clase Comunicación e Interactividad (2019-2, 2020-1, 2020-2 y 2021-1), en el análisis del caso reflexiono sobre el proceso de construcción de un espacio de afinidad y sobre el diseño e implementación de un blog colectivo. Por medio del análisis de los contenidos e interacciones que se crearon en el espacio de afinidad, particularmente en el blog, indago sobre las posibilidades para la enseñanza y el aprendizaje que ofrece diseñar entornos centrados en la producción, conectados en red y con un propósito compartido. Los resultados del estudio confirman que el blog colectivo es una herramienta útil para construir espacios de afinidad, promover el aprendizaje conectado y desarrollar aulas híbridas.

PALABRAS CLAVE: espacio de afinidad / aprendizaje conectado / blog / aula híbrida / innovación educativa

\footnotetext{
* Doctor en Media Studies por The University of Texas at Austin, Estados Unidos (véase: https://orcid. org/0000-0002-1246-5994).
} 


\section{THE COLLECTIVE BLOG AS A PORTAL TO AN AFFINITY SPACE: DEVELOPING THE HYBRID CLASSROOM IN A UNIVERSITY COURSE IN COLOMBIA}

ABSTRACT. The article presents a case study of a hybrid classroom experience in a university class of Social Communication in Colombia, in which an affinity space was built through the use of information and communication technologies (ICT). Using the theories of affinity space (Gee, 2003, 2005, 2017) and connected learning (Ito et al., 2013) and based on qualitative data collected during four iterations of the class "Communication and Interactivity" (2019-2, 2020-1, 2020-2 and 2021-1), the case reflects on the process of building an affinity space and on the design and implementation of a collective blog as a tool for teaching and learning. By analyzing of the contents and interactions created in the affinity space, particularly in the blog, I inquire about the possibilities for innovation offered by designing environments that are productioncentered, networked, and that have a shared purpose. The study results confirm that a collective blog is a useful tool for building affinity spaces, promoting connected learning, and developing hybrid classrooms.

KEYWORDS: affinity space / connected learning / blog / hybrid classroom / educational innovation

\section{O BLOGUE COLETIVO COMO PORTAL NUM ESPACO DE AFINIDADE: DESENVOLVER A SALA DE AULA HÍBRIDA NUMA DISCIPLINA UNIVERSITÁRIA NA COLÔMBIA}

RESUMO. 0 artigo apresenta um estudo de caso de uma experiência de sala de aula híbrida numa disciplina universitária de Comunicação Social na Colômbia, na qual foi construído um espaço de afinidade por meio da utilização de Tecnologias de Informação e Comunicação (TIC). Usando as teorias do espaço de afinidade (Gee, 2003, 2005, 2017), da aprendizagem conectada (Ito et al., 2013) e com base em dados qualitativos recolhidos durante quatro interações da disciplina "“Comunicación e Interactividad" (2019-2, 20201, 2020-2 e 2021-1), o caso reflete sobre o processo de construção de um espaço de afinidade e sobre a concepção e implementação de um blog coletivo como instrumento de ensino e aprendizagem. Mediante a análise do conteúdo e das interações que foram criadas no espaço de afinidade, particularmente no blogue, exploro as possibilidades de inovação na concepção de ambientes centrados na produção, conectados em rede e com um propósito partilhado. Os resultados do estudo confirmam que o blogue coletivo é uma ferramenta útil para a construção de espaços de afinidade, promovendo a aprendizagem conectada e o desenvolvimento de salas de aula híbridas.

PALAVRAS-CHAVE: espaço de afinidade / aprendizagem conectada / blogue / sala de aula híbrida / inovação educacional 


\section{INTRODUCCIÓN}

La transformación tecnológica y la consolidación de un ecosistema mediático en red y convergente ha motivado el desarrollo de nuevos modelos de aprendizaje y enseñanza. Aunque la transformación de la educación ya venía pensándose desde los siglos XIX y XX, las nuevas tecnologías del siglo XxI han contribuido a una mayor experimentación e innovación a la hora de pensar y desarrollar los procesos de aprendizaje y enseñanza. Estos nuevos modelos han recogido los desarrollos teóricos de pedagogías constructivistas, construccionistas, situadas, críticas, entre otras. Asimismo, como resultado del avance de las investigaciones y del proceso de integración de las tecnologías de la información y la comunicación (TIC) en los sistemas educativos, han surgido nuevas modalidades de educación como la virtual o en línea, la blended o mezclada, y la híbrida.

La integración de las TIC en los sistemas educativos, sin embargo, varía de acuerdo a las características de los contextos nacionales y locales. En contextos caracterizados por profundas brechas digitales de acceso, conectividad, apropiación y conocimiento, el uso de las TIC en la educación está marcado por la desigualdad. En Colombia, un país donde solo el $43,4 \%$ de la población tiene acceso a internet -la mayoría a través de teléfonos móviles (Ministerio de Tecnologías de la Información y las Comunicaciones, 2020) - y donde los niveles de apropiación de las TIC son bajos (Centro Nacional de Consultoría [CNC], 2020), el desarrollo de las nuevas modalidades de educación ha ocurrido sobre todo en instituciones educativas localizadas en centros urbanos' ${ }^{1}$. Es particularmente en las universidades, con grupos poblacionales que tienen acceso a infraestructura tecnológica y conocimientos, donde diversas experiencias de educación virtual, blended e híbrida han sido desarrolladas progresivamente desde finales de los años noventa. En la actualidad, por ejemplo, las principales universidades del país promueven el uso de software (como Moodle y Blackboard) para apoyar la gestión y desarrollo de clases virtuales, así como las que combinan presencialidad y virtualidad en modalidades híbridas (Galvis et al., 2016; Acevedo-Rincón y Flórez-Pabón, 2020). Sin embargo, las investigaciones sobre estos tipos de innovación educativa, su impacto en los aprendizajes, las pedagogías y las didácticas, así como el análisis de los procesos de diseño e implementación, son escasas.

En este artículo presento un estudio de caso sobre un aula híbrida que diseñé e implementé en una clase de Comunicación Social en la Universidad Javeriana, una institución privada de educación superior con sede en Bogotá, Colombia. A manera de preámbulo al

1 Los estudios realizados por el CNC en Colombia han diagnosticado índices de apropiación digital bajos (0,20 en el 2016, 0,22 en el 2018, y 0,23 en el 2020, escala 0-1); esto revela que la mayoría de la población utiliza las TIC con fines de entretenimiento y comunicación básica. Solo una minoría hace uso de ellas para actividades complejas como la educación, la colaboración y transacciones financieras. Esta población minoritaria es principalmente urbana y de estratos socioeconómicos altos (CNC, 2020). 
caso, discuto la utilidad del concepto de espacio de afinidad para diseñar aulas híbridas, la relación de este concepto con el aprendizaje conectado y las características del blog, una de las TIC con mayor potencial para la educación. A continuación, describo mi aproximación metodológica y los datos recolectados durante cuatro iteraciones de la clase. En el estudio de caso, elaboro una reflexión sobre la arquitectura del espacio de afinidad de la clase y analizo el proceso de diseño e implementación del blog colectivo, indagando en las interacciones y en los contenidos creados en y con esta herramienta.

\section{Espacios de afinidad para el aula híbrida}

Una de las nuevas modalidades de educación en las que el espacio de aprendizaje y enseñanza se expande más allá de las cuatro paredes del aula presencial, a través del uso y la mediación de las TIC, es el aula híbrida. En esta modalidad, el espacio de las aulas presenciales, caracterizado por procesos cara a cara, se amplía mediante el uso de las TIC (Asinsten, 2013; Duart et al., 2008; Mejía Gallegos et al., 2017; Osorio, 2010). Como afirma Osorio (2010), los ambientes híbridos combinan la presencialidad con la virtualidad integrándolas de forma inseparable, extendiendo el continuo espacio-temporal del aula. Por ejemplo, el modelo presencial se expande al utilizar herramientas como las páginas web, las plataformas de aprendizaje digitales (por ejemplo, Moodle, Blackboard), los correos electrónicos y los chats, extendiendo las interacciones, actividades y procesos de estudiantes y profesores. El aula híbrida integra algunas de las herramientas y dinámicas del modelo de educación virtual al modelo presencial, dando continuidad espacio-temporal a un ambiente de aprendizaje que se expande dentro y fuera del salón de clase, de forma sincrónica y asincrónica.

El concepto de espacio de afinidad es útil para entender el tipo de interacciones, pedagogías, didácticas y procesos de aprendizaje que pueden desarrollarse en el aula híbrida. Un espacio de afinidad es un lugar físico o digital, o una mezcla de lugares, en donde un grupo de personas se encuentra para interactuar con base en intereses, actividades y objetivos comunes (Gee, 2003, 2005, 2017). Según Gee (2005), el principal proponente de este concepto, "un espacio de afinidad es un lugar o conjunto de lugares donde las personas se afilian con otros basándose principalmente en actividades, intereses y objetivos compartidos" (p. 67). Partiendo de la premisa de que la enseñanza y el aprendizaje se distribuyen en muchos lugares, personas y prácticas, el espacio de afinidad se entiende como un concepto flexible, que puede inclusive incluir espacios híbridos que mezclan lo físico y lo virtual (Gee, 2005, 2017).

Aunque este tipo de espacios ha existido desde antes de la aparición de las TIC, su conceptualización ha sido desarrollada en las últimas décadas como resultado de la investigación en los procesos de aprendizaje informal, los nuevos alfabetismos y las prácticas socioculturales que tienen lugar en internet. Es precisamente Gee quien, estudiando el discurso y el aprendizaje como procesos socioculturales situados y mediados 
por tecnología, creará el concepto de espacios de afinidad para explicar otras formas de organizar el aprendizaje, la enseñanza y la producción de conocimiento diferentes a las de la escuela tradicional. Este concepto se nutre de teorías socioculturales (por ejemplo, Freire, 1974; Lave y Wenger, 1991; Vygotsky, 1978) que entienden el aprendizaje y la alfabetización como procesos activos, situados y dialógicos, en los que se construyen identidades, se crea significado y se tejen relaciones sociales en contextos históricos, sociales y políticos específicos.

Dado que la participación juega un papel central para los procesos de aprendizaje que ocurren en los espacios de afinidad, podría pensarse que estos entornos son iguales a las "comunidades de práctica" descritas por Lave y Wenger (Lave y Wenger, 1991; Wenger, 1998). Sin embargo, su diferencia radica en que los espacios de afinidad no requieren de membresía o pertenencia a una comunidad. De acuerdo con Gee (2005), la membresía puede limitar las dinámicas de un grupo e incluso excluir, porque connota un sentido de pertenencia a una comunidad, definido como enlaces personales entre miembros, lo cual no siempre ocurre en las dinámicas del aula. El concepto propuesto por Gee, en contraste, hace énfasis en el espacio y la interacción, no en la comunidad, y tiene la intención de promover la participación democrática en los procesos de aprendizaje de todas las personas independientemente de su pertenencia a un grupo, una clase social, un género o una raza. En lugar de pensar a los participantes como miembros de una comunidad, Gee nos propone pensarlos como personas diversas, con diferentes niveles de experticia, que interactúan en un espacio impulsados por un interés común.

Los espacios de afinidad son lugares en donde las personas actúan, enseñan, aprenden y producen diversos tipos de artefactos, sin tener en cuenta las credenciales, las edades, las razas y los grados de experiencia. Por ende, son espacios democráticos que permiten la existencia de diferentes formas y vías de participación, y de muchas maneras posibles de obtener un determinado estatus relacionado con el conocimiento de temas específicos y la habilidad para producir ciertos tipos de contenidos (Gee, 2005, 2017).

\section{Aprendizaje conectado y nuevos alfabetismos}

Asumiendo que la enseñanza y el aprendizaje se distribuyen en muchos lugares, personas y prácticas, el desarrollo teórico sobre los espacios de afinidad ha privilegiado el estudio de los procesos de aprendizaje informal que ocurren fuera de las instituciones educativas tradicionales. Ha sido a través de las investigaciones sobre los nuevos alfabetismos, las prácticas mediáticas y los artefactos generados por las culturas participativas que han proliferado en internet (por ejemplo, fans, gamers y escritores de ficción), que los espacios de afinidad han sido conceptualizados y caracterizados (Black, 2005; Curwood, 2013; García-Roca, 2016; Gee, 2005, 2017; Ito et al., 2010; Jenkins, 2009; Lugo et al., 2017; Magnifico et al., 2018). 
Particularmente, las investigaciones sobre el desarrollo de nuevos alfabetismos han servido para identificar y analizar las interacciones, prácticas y artefactos desarrollados en los espacios de afinidad. Recordemos que los "estudios sobre nuevos alfabetismos" (New Literacy Studies, en inglés), de los cuales Gee ha sido pionero, han propuesto desde finales de 1980 el entendimiento de los alfabetismos como prácticas socioculturales e históricas desarrolladas por personas y grupos. Esta perspectiva interdisciplinaria combina la lingüística, la sociología, la antropología, la retórica, entre otras áreas, para entender la alfabetización como un proceso sociocultural e histórico, y no como un mero proceso mental y cognitivo. Los estudios sobre nuevos alfabetismos reconocen la existencia de múltiples tecnologías con las que se crea y comunica significado y con las que se desarrollan diversas prácticas socioculturales (Gee, 2015). Esta aproximación ha sido bastante generativa al promover el reconocimiento, teorización y estudio de diversos tipos de alfabetismos o prácticas socioculturales, tales como los multialfabetismos (Cope y Kalantzis, 2000), los nuevos alfabetismos mediáticos (Jenkins, 2009), los alfabetismos digitales (Lankshear y Knobel, 2006) y los alfabetismos transmedia (Scolari, 2016).

Como entornos socioculturales, los espacios de afinidad permiten el aprendizaje y el desarrollo de nuevos alfabetismos a través de diferentes formas de participación, interacción y colaboración. En estos entornos los participantes comparten un interés que los conecta y los motiva a participar, aprender y resolver problemas. Los espacios de afinidad, nos recuerda Gee (2017), "se definen principalmente por la afinidad para resolver ciertos tipos de problemas. Como tales, siempre implican el desarrollo de ciertos tipos de habilidades" (p. 28). Es precisamente la resolución de problemas y el desarrollo de proyectos comunes lo que fomenta un aprendizaje de tipo social y el desarrollo de habilidades a través de la participación. La resolución de problemas y los proyectos comunes facilitan la colaboración y enseñanza entre pares, motivando a los participantes del espacio a adquirir nuevos conocimientos, perfeccionar sus habilidades existentes, y a sentirse como expertos mientras aprovechan la experiencia de los demás (Jenkins, 2009).

Ahora bien, aunque en la actualidad existen varios modelos de aprendizaje (por ejemplo, conectivo, invisible, para toda la vida) que reconocen el carácter híbrido e interconectado de los procesos educativos, valorando igualmente las experiencias dentro y fuera de la escuela, y los contextos formales e informales, la propuesta de "aprendizaje conectado" (connected learning, en inglés) es una de las más apropiadas para entender el alcance del concepto de espacios de afinidad. Desarrollada por un grupo de académicos norteamericanos y británicos en el marco de la iniciativa Digital Media and Learning de la MacArthur Foundation, esta propuesta adelanta un modelo de aprendizaje basado en teorías constructivistas, situadas y socioculturales de la educación y el aprendizaje. Este modelo es parte de una agenda de investigación y diseño que busca promover la igualdad de oportunidades en el sistema educativo formal e informal, la participación 
de estudiantes en múltiples dimensiones sociales y la creación de conexiones (Ito et al., 2013, 2020).

El aprendizaje conectado se guía por tres principios. El primero de ellos es valorar las pasiones de los estudiantes y entenderlas como fuerzas motivadoras en la adquisición de conocimientos y experiencias. El segundo es apoyar la interacción, participación y colaboración entre compañeros (apoyo de pares). El tercer principio reconoce la importancia de lo académico para el crecimiento intelectual y la adquisición de oportunidades económicas. Como puede apreciarse, estos tres principios están fuertemente inspirados por el concepto de espacios de afinidad y buscan potenciar las interacciones, prácticas y actividades que varios investigadores han encontrado al estudiar estos espacios (Gee, 2005, 2017; Jenkins, 2009; Ito et al., 2010, 2018). Por ejemplo, el aprendizaje conectado reconoce que los intereses de los estudiantes son fundamentales para conectar múltiples contextos (como hogar, escuela, universidad, cultura popular, comunidad) y para impulsar los procesos educativos en red. Asimismo, valora los procesos de creación y producción que caracterizan las culturas participativas como prácticas fundamentales para el desarrollo de habilidades y conocimientos.

\section{Los blogs como herramienta en la educación superior}

Un blog puede definirse como un sitio o página web personal en el que las personas publican de forma regular contenidos (usualmente las entradas están en formato de texto, pero también pueden incluir imágenes, videos, hipervínculos y otro tipo de contenido) y compartirlos en línea con amigos, familiares y con otras personas que tengan acceso a internet. Las entradas o publicaciones de un blog se muestran en orden cronológico inverso: en la página principal aparecen las más recientes. Estas publicaciones se organizan en un archivo de entradas de acuerdo con su fecha de publicación. Todas las publicaciones pueden accederse a través de hipervínculos. Por su facilidad de uso y acceso, los blogs pueden utilizarse con pocos conocimientos técnicos, crearse en pocos minutos, y son fáciles de personalizar y actualizar.

Aunque el uso de blogs se extendió en los noventa a través de instalaciones de software en servidores personales, el lanzamiento en 1999 de plataformas que ofrecían gratuitamente el servicio de alojamiento de weblogs (Live Journal y Blogger) aceleró su popularización. Estas plataformas y otras que ofrecen servicios similares (como WordPress y Tumblr) contribuyeron a que los blogs se convirtieran en una de las principales herramientas de publicación en la web². Hoy en día los blogs son utilizados por

2 Evidencia de la popularidad de esta herramienta es la introducción de términos como blogosfera (blogosphere en inglés) para referirse a la comunidad creada por la red de blogs que intercambiaban información y participaban en discusiones, y bloguear (blogging en inglés) para referirse a la acción que realiza un bloguero/a (blogger) al crear y administrar un blog. 
una gran variedad de personas alrededor del mundo. Desde músicos hasta publicistas, creadores de contenido de todas las edades utilizan blogs para publicar y compartir sus opiniones, ideas y contenidos en internet. Tal diversidad de usos se ve reflejada en la variedad de formatos y géneros que tienen los blogs actualmente. Por ejemplo, algunos pueden tomar la forma de periódicos hiperlocales, otros la de recetarios de cocina, y otros la de guías turísticas. En el contexto académico y de los sistemas educativos, los blogs han sido una de las TIC que más fácilmente han sido apropiadas por todos los actores del ecosistema (estudiantes, profesores, administradores, directivos) alrededor del mundo. En la actualidad varias universidades e instituciones de educación superior proveen la infraestructura para alojar blogs de estudiantes y docentes, y han promovido el uso de blogs en clases y como parte de las estrategias comunicacionales de diferentes unidades académicas y administrativas.

El uso de blogs en la educación superior ha motivado varias investigaciones, sobre todo en Norteamérica y Europa, en las últimas décadas. Enfocándose en las dinámicas de participación que ocurren en los blogs educativos, algunos autores han identificado tres modalidades (Nackerud y Scaletta, 2008; Sim y Hew, 2010): (1) el blog del profesor, utilizado para publicar anuncios, enlaces y materiales; (2) el blog colectivo de la clase creado y gestionado colaborativamente por el profesor y los estudiantes; y (3) el blog individual utilizado como portafolio o espacio de expresión de cada alumno. La modalidad de "blogs gestionados por el instructor y los alumnos" es, según Nackerud y Scaletta (2008), la más eficaz de las tres, especialmente cuando logra involucrar a los alumnos en el desarrollo de contenidos del curso.

Con relación a los beneficios del uso de blogs en los procesos de aprendizaje, las investigaciones realizadas hasta ahora han demostrado que estas herramientas ofrecen oportunidades para la reflexión y la expresión individual de estudiantes y profesores (Deng y Yuen, 2011; Ferdig y Trammell, 2004). Dado que la expresión en los blogs puede ocurrir de forma multimodal, integrando textos, imágenes, audios o incluso videoclips, los blogs pueden funcionar como entornos de aprendizaje constructivista en donde los estudiantes publican y comparten artefactos que son resultados de su hacer (Wang et al., 2012). De acuerdo con Boyd (2013), los blogs fomentan que los estudiantes se apropien de sus textos, promueven el pensamiento crítico (análisis, evaluación y síntesis), y pueden ayudar a que la construcción de conocimiento se centre en el estudiante y no en el profesor.

Varias investigaciones han confirmado que los blogs fomentan la interacción, la participación y el aprendizaje colaborativo (Deng y Yuen, 2011; García et al., 2015). Gracias a sus características técnicas, los blogs pueden utilizarse para procesos de aprendizaje colaborativo en los que se intercambian ideas, se crean redes sociales y se trabaja en grupo para producir y compartir conocimientos (Cheng y Chau, 2011; García et al., 2015; 
Hall y Davison, 2007). Sin embargo, a pesar de su potencial para facilitar la interacción y participación, algunos estudios han encontrado que los estudiantes no siempre están dispuestos a publicar comentarios, discutir y dar retroalimentación a sus pares en el espacio de los blogs (Hall y Davison, 2007; Xie et al., 2008).

Ahora bien, como lo reflejan los hallazgos encontrados por las investigaciones sobre blogs educativos, esta herramienta es eficaz para apoyar la implementación de un modelo de educación que expande el aprendizaje más allá de las cuatro paredes del aula, promueve la reflexión individual y la interacción social, e incentiva la participación de estudiantes en la construcción de conocimiento. Por ende, son tecnologías apropiadas para facilitar el aprendizaje conectado y la construcción de espacios de afinidad. Aunque las investigaciones sobre blogs educativos no han abordado directamente el concepto de espacios de afinidad, los estudios sobre culturas participativas sí lo han hecho. Investigaciones sobre las culturas de jugadores de videojuegos, escritoras amateur de ficción fanática (fan fiction) y creadores de memes, por ejemplo, han demostrado que los blogs son parte importante de los espacios de afinidad donde los jóvenes crean significado y desarrollan nuevos alfabetismos fuera de la escuela (Gee, 2003, 2005, 2017; Ito et al., 2010; Jenkins, 2009; Lankshear y Knobel, 2006; Lammers et al., 2012). Asimismo, recientes investigaciones sobre aprendizaje conectado han demostrado que los blogs pueden facilitar un aprendizaje centrado en los intereses de los aprendices que promueve relaciones sociales y abre oportunidades de tipo académico, cívico y profesional (Stephens, 2016; Ito et al., 2018; Kafai y Burke, 2016).

\section{METODOLOGÍA}

La metodología de esta investigación es cualitativa. Por un lado, para elaborar el estudio de caso utilizo el método de la reflexión (Dewey, 1916; Fook, 1999; Mortari, 2015), analizando pragmática y críticamente mi experiencia en la construcción de un espacio de afinidad y el diseño e implementación de un blog colectivo. Por otro, realizo un análisis cualitativo de los materiales de aprendizaje diseñados para la clase, particularmente los desafíos semanales, y los artefactos digitales creados por los estudiantes y publicados en el blog. Algunos de estos artefactos son examinados con el método de análisis del discurso multimodal (Kress, 2010; Kress y Van Leeuwen, 2001).

El estudio de caso se basa en datos recolectados durante cuatro iteraciones de la clase Comunicación e Interactividad en la Universidad Javeriana (2019-2, 2020-1 y 2; 2021-1). Estos datos incluyen los contenidos (artefactos digitales) publicados por estudiantes en el blog colectivo, las observaciones de las interacciones sincrónicas y asincrónicas de los participantes, y los materiales de aprendizaje (guías, tutoriales, desafíos) que utilicé en cada versión del curso. 
El blog colectivo ha sido desarrollado y gestionado utilizando la plataforma Tumblr ${ }^{3}$. Cada una de sus iteraciones se ha publicado abiertamente en la red ${ }^{4}$. Todas las publicaciones y contenidos realizados en el blog cuentan con licencias Creative Commons que permiten su reproducción. En la tabla 1 se presentan los datos de los artefactos digitales recolectados en las cuatro iteraciones del blog colectivo, y se indica el total de semanas en el que se motivó la publicación de contenidos a través de desafíos, y el número de participantes.

Tabla 1

Datos de las cuatro iteraciones del blog colectivo

\begin{tabular}{lccc}
\hline Semestre & Estudiantes participantes & Semanas con desafíos & Entradas/artefactos digitales publicados \\
\hline $2019-2$ & 27 & 12 & 142 \\
$2020-1$ & 29 & 12 & 237 \\
$2020-2$ & 32 & 12 & 229 \\
$2021-1$ & 35 & 12 & 340 \\
Total & 123 & 48 & 948 \\
\hline
\end{tabular}

Elaboración propia

\section{ESTUDIO DE CASO}

Comunicación e Interactividad es una asignatura de pregrado en la Universidad Javeriana cuyo objetivo es introducir conceptos y teorías que permitan a los estudiantes analizar y entender el funcionamiento de los medios interactivos y su impacto en la sociedad, la cultura, la ética y la política. Aunque el curso es ofrecido por el Departamento de Comunicación y es parte del plan de estudios de la carrera de Comunicación Social, está abierto a estudiantes de otras facultades que pueden tomarlo como electivo. Muchos de los participantes de la clase, por ejemplo, provienen de las Facultades de Diseño Industrial y Artes.

3 Creada por el desarrollador y emprendedor estadounidense David Karp en el 2007 en medio del auge de la web 2.0 y el surgimiento de sitios de redes sociales como YouTube, Facebook y Twitter en Estados Unidos, Tumblr se popularizó rápidamente luego de ser lanzada como una plataforma de microblogging para publicar y compartir textos, imágenes, enlaces y videos. Por su diseño y funcionalidad, que integra características de las redes sociales dedicadas al contenido generado por usuarios y las de los blogs tradicionales, Tumblr se convirtió en una de las plataformas preferidas por usuarios jóvenes que valoran y practican el lenguaje multimodal utilizando imágenes, GIF animados, videos y textos (González, 2019).

4 Las cuatro versiones del blog colectivo son públicas y pueden ser consultadas por cualquier persona con acceso a internet en las siguientes direcciones: https://comunica-inter4ctive2021.tumblr. $\mathrm{com} /$; https://cumunicainteractividad2020.tumblr.com/; https://cumunicacioninteractividad2020. tumblr.com/; https://comunica1nteract1ve.tumblr.com/ 
Aunque Comunicación e Interactividad está planteada originalmente para desarrollarse de forma presencial, con encuentros presenciales de tres horas, la crisis del COVID-19 y el cierre del campus universitario desde marzo del 2020 hizo que la clase se adaptara rápidamente a un modelo de educación a distancia. De las cuatro iteraciones del curso que utilizo en este caso de estudio, dos de ellas fueron desarrolladas en encuentros sincrónicos telepresenciales (2020-2, 2021-1), una combinó encuentros presenciales y telepresenciales (2020-1), y la otra tuvo encuentros presenciales semanales (2019-2). Sin embargo, hay que aclarar que en todas las iteraciones del curso se desarrolló un modelo de aula híbrida, en el que los encuentros sincrónicos, bien fueran presenciales o telepresenciales, se complementaron con interacciones asincrónicas en espacios virtuales como el blog colectivo, el correo electrónico y el entorno del curso en Blackboard (plataforma oficial de la Universidad Javeriana).

Desde el primer semestre que tuve la oportunidad de dictar el curso Comunicación e Interactividad, decidí experimentar con un modelo de aula híbrida que no solo expandiera el espacio físico con espacios virtuales facilitados por las TIC, sino que también mezclara teoría y práctica, combinando las dinámicas del seminario académico tradicional con las del laboratorio/taller de medios. De esta forma, los conceptos y teorías discutidas en las dinámicas del seminario podrían ser también aplicados a través de la creación de artefactos digitales y el desarrollo de proyectos individuales y en grupo. El desarrollo de este modelo de aula híbrida se encuentra fuertemente influenciado por la teoría de espacios de afinidad y por los principios de diseño del aprendizaje conectado, y recoge mis experiencias como investigador y diseñador en iniciativas como el Project New Media Literacies, la Connected Learning Research Network y el Youth and Media Lab.

\section{Arquitectura del espacio de afinidad}

El espacio de afinidad, como lugar o conjunto de lugares físicos o virtuales, está compuesto por varios elementos que deben ser diseñados y estructurados para facilitar y promover la interacción, la participación y el aprendizaje en torno a un interés común. De acuerdo con Gee (2007), los principales componentes de un espacio de afinidad son el contenido, los generadores y los portales.

El contenido hace referencia a la temática y problemática del espacio. En el caso de Comunicación e Interactividad, el contenido se enfocó en las transformaciones sociales, políticas, éticas y culturales que han producido el uso y apropiación de las TIC. Esta temática y los contenidos asociados se plantearon de tal forma que conectaban los conceptos y teorías académicas con las prácticas mediáticas cotidianas y conocimientos empíricos de los estudiantes. Por ende, el contenido incluyó no solo libros y artículos académicos y seleccionados por el profesor (bibliografía), sino también textos, presentaciones y artefactos digitales producidos y seleccionados por los estudiantes durante el desarrollo del curso. 
Además, dentro de los contenidos del espacio del curso incluí una serie de recursos de aprendizaje como guías de talleres, desafíos semanales y presentaciones multimedia que como profesor he tenido la oportunidad de diseñar. Estos materiales los he creado y ajustado cada semestre para fomentar la participación y las interacciones de los estudiantes. Como afirma Gee (2017), el arquitecto del espacio de afinidad debe diseñar un conjunto de problemas bien definidos y desafiantes. Estos desafíos deben exaltar el propósito e interés común del espacio, y al mismo tiempo conectar los intereses y pasiones de los participantes.

Ahora bien, los generadores de un espacio de afinidad pueden entenderse como todas las personas que participan aportando contenidos y creando relaciones. En Comunicación e Interactividad todos los estudiantes y el profesor fueron generadores, participando en el espacio a través de diferentes interacciones (como presentaciones multimedia, discusiones de lecturas, trabajos en grupo) y produciendo y compartiendo diversos tipos de contenido (por ejemplo, reseñas de lecturas, artefactos digitales).

Los portales, por su parte, son los lugares, tanto físicos como virtuales, donde los participantes del espacio de afinidad pueden acceder al contenido y donde interactúan con otros. Los portales dan forma al discurso y a las interacciones en el espacio de afinidad (Gee, 2007). Para el curso Comunicación e Interactividad se estructuraron inicialmente tres portales: (1) el espacio físico del aula, (2) el espacio virtual del curso en Blackboard y (3) el espacio del blog colectivo. Sin embargo, durante el contexto de pandemia, el espacio físico del aula fue reemplazado por un espacio virtual de videoconferencia y de comunicación sincrónica.

La arquitectura del espacio de afinidad define rutas para que los participantes puedan "viajar" a los diferentes portales y de esta forma interactuar con los contenidos y crear relaciones (Gee, 2007). Una de las rutas más importantes que diseñé entre los portales de Comunicación e Interactividad es la que realizamos durante los encuentros sincrónicos, cuando todos los participantes podemos visitar el blog colectivo, proyectarlo en la pared del salón físico o en las pantallas de nuestros dispositivos en casa, y discutir los artefactos digitales que los estudiantes han producido de acuerdo con el desafío y temática abordada cada semana.

\section{Diseño e implementación del portal del blog colectivo}

Por sus características técnicas y las prácticas socioculturales asociadas a su uso, la herramienta del blog ofrece amplias posibilidades para la construcción de portales en un espacio de afinidad. Los blogs son TIC altamente interactivas y sociales que permiten a las personas crear y publicar contenidos, desarrollar relaciones y establecer conexiones a través de la gestión y construcción de un sitio web. En su formato colectivo, la herramienta extiende estas posibilidades a un conjunto de usuarios, potenciando la participación, la colaboración y la interacción de un grupo específico de personas. 
Las cuatro iteraciones del blog que utilizo para elaborar el estudio de caso forman parte de un proceso iterativo en el cual busqué fomentar las dinámicas que caracterizan un espacio de afinidad y aplicar los principios de diseño del aprendizaje conectado. Específicamente, en el diseño del blog intenté construir un espacio flexible y abierto a la participación, el cual, enfocado en un propósito común, promueve el conocimiento individual y distribuido; fomenta la creatividad y producción de contenidos; apoya el establecimiento de relaciones sociales, y valora la diversidad de géneros, edades y etnias de todos los estudiantes participantes. A continuación, presento un análisis de las características técnicas, las interacciones y los artefactos digitales que caracterizan el blog colectivo.

\section{Características técnicas}

Dentro de la variedad de plataformas para diseñar e implementar el blog de Comunicación e Interactividad elegí Tumblr por varias razones. Primero, es una plataforma libre y abierta, disponible en la web para cualquier usuario que tenga conexión a internet y es de fácil acceso desde múltiples dispositivos (computadora, teléfono móvil, tablet, etcétera). Segundo, Tumblr tiene una interfaz intuitiva, bien sea a través del navegador web o de una aplicación para dispositivos móviles, que permite crear y gestionar blogs personales y colectivos de manera relativamente sencilla. Tercero, la plataforma permite la publicación de contenidos multimodales combinando textos, audios, videos y fotos. Cuarto, Tumblr ofrece a los usuarios una capacidad de almacenamiento de datos casi ilimitada (el único límite es el número de contenidos publicados al día, por ejemplo, setenta y cinco posts de fotos por día), facilitando la publicación y alojamiento de archivos multimedia sin ningún costo ${ }^{5}$.

Una de las funcionalidades de Tumblr es que permite crear y gestionar blogs colectivos con relativa facilidad. Cualquier usuario registrado en la plataforma puede generar un nuevo blog desde su panel de control y, a continuación, invitar a otros usuarios de Tumblr a unirse a él como colaboradores. La invitación se realiza utilizando los correos electrónicos o los nombres de usuario de los participantes. Una vez que los usuarios han sido añadidos como colaboradores, estos pueden empezar a publicar contenidos directamente en el blog colectivo sin ningún tipo de restricción ${ }^{6}$.

5 Una razón adicional para la elección de Tumblr como infraestructura es mi propia experiencia y conocimiento de la plataforma. Por más de una década la he utilizado en proyectos y experimentos creativos personales y en intervenciones educativas realizadas con jóvenes de escuela secundaria. Estas experiencias me han demostrado su potencial para facilitar procesos de creación, enseñanza y aprendizaje.

6 Tumblr ofrece también la posibilidad de dar privilegios de administrador a los usuarios que han sido adicionados al blog colectivo, lo cual les permite editar contenidos de otros usuarios, borrar contenidos y modificar la apariencia del blog. Sin embargo, esta función no fue habilitada para el blog de Comunicación e Interactividad y el único usuario administrador fue el docente. 


\section{cOm + \\ interactividad}

PLAN BiBLIOGRAFA SOBREEL BLO
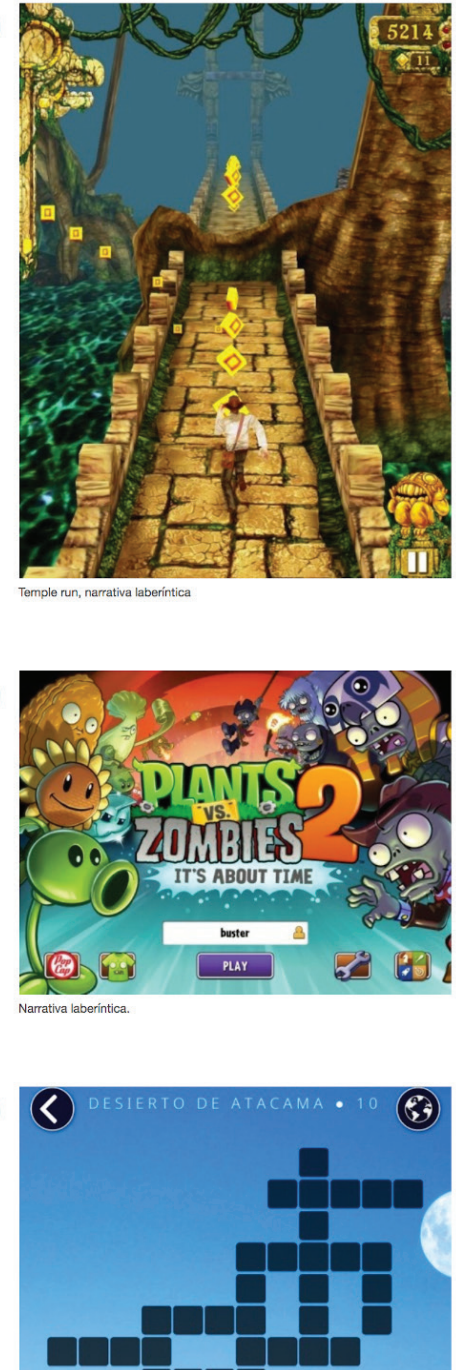

comunicación + interactividad 2020-1
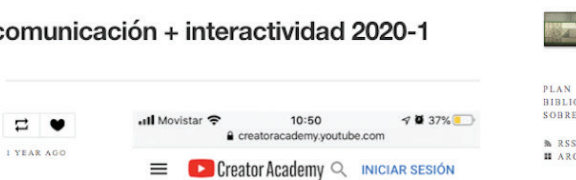

$\substack{\text { RLAN } \\ \text { BIBHOCORA }}$

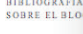

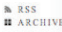

alguna de las directrices o politicas especificas de YouTube

Políticas por las que se rige YouTube

Normas de la comunidad

Derechos de autor

Contenido con restricción de edad

Politicas de monetización

Resumen
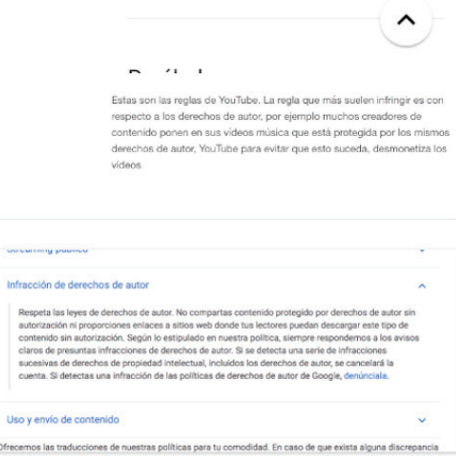

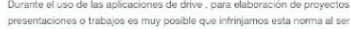

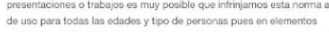
chiciales o de tipo hboral o edvucativo puede que se tenga en cuenta asta

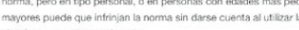
platatorma para temas de ocio.

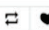

\section{.. 400}

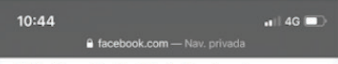

23. Propiedad intelectual

Facebook se toma muy en serio los derechos de propiedad intelectual y considera que son importantes para fomentar la expresión, creatividad e innovación en nuestra comunidad.

Tú eres el propietario de todo el contenido y la información que 

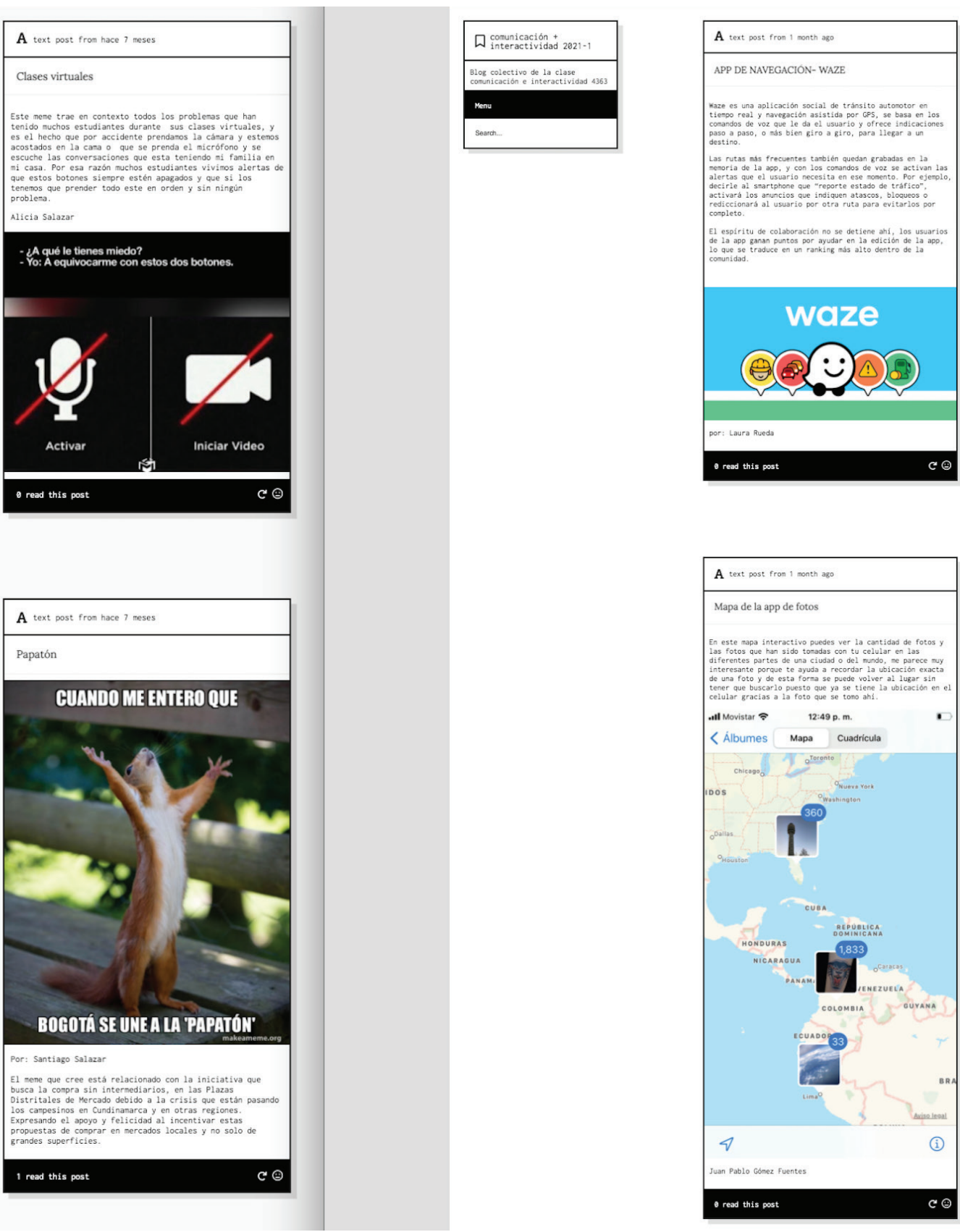

Figura 1. Diseños de la apariencia del blog (de izquierda a derecha: 2019-2, 2020-1, 2020-2 y 2021-1)

Fuente: Reproducido del blog colectivo del curso Comunicación e Interactividad 2019-2, 2020-1, 2020-2, 2021-1 (https://comunica-inter4ctive2021.tumblr.com/; https://cumunicainteractividad 2020.tumblr.com/; https://cumunicacioninteractividad2020.tumblr.com/;https://comunica1nteract 1ve.tumblr.com/) 
comunicación + interactividad 2021-1 $\mid$ Month $\vee \mid$ Post type $\vee \mid$ Tag

February 2021

La obra de arte y

la

reproducibilidad mecánica

En este caso, esta

bra de Jesús Abad

Number 17A

Jackson Pollock
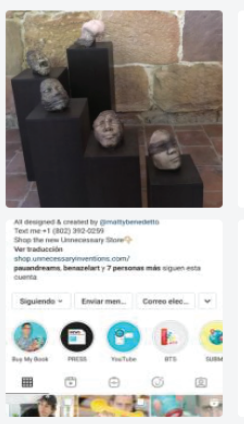

Comunidad Online

en Whatsapp-club 5 am

el grupo de

whatsapp de

club5am es un lugar

Thank you, next.

Medios frios y calientes

Medios caliente:

Tienen mucha

información y no

favorece la

medio caliente:

fotografia la

fotografia es un

medio caliente ya

que tiene mucha

informacion y no
The Work of Art in

the Age of

Mechanical

Reproduction

SILK PAVILION -

Pabellón de seda

\section{Charles}

Pintura oleo sobre

lienzo de Jardan

Casteel,

exhibida The Studio

Museum in Harlem

The Making Soap

ALFABETISMO

MEDIÁTICO-

@danielasalcedo2

22 TikTok

Por: Mariana

Gutiérrez

ALFABETISMO

MEDIÁTICO -

COMUNIDAD

ONLINE

El grupo de

Facebook mundos

\section{Nuevos}

alfabetismos

mediáticos.

Centro de

adopciones de

Bogotá, es un grupo

Medios fríos y

calientes.

McLuhan, $\mathrm{M}$.

Medio caliente: la

radio, 'Fantastica',

104.4 fm: es el

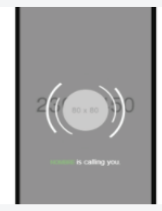

Coreografía del grupo filipino

VPeepz

Este grupo está

compuesto de niños

entre 9 y 15 años de

Jesus Abad

Colorado

Esta obra fue

realizada por Jesus

Abad Colorado y

estuvo expuesta a

Black Panther

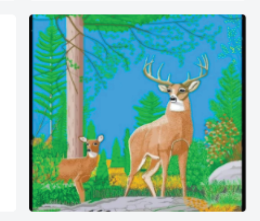

\section{Cultura}

participativa -

Alfabetismo

mediático

El grupo Crece Tu

Agencia de

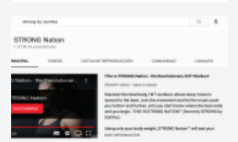

a. 1

Comunidad

online

Este perfil en la

plataforma Tik tok

,permite a sus

seguidores tener

Medios fríos y medios calientes

Medio caliente:

Netflix

En esta plataforma

de contenidos

Comprender los

medios de

comunicación

Los medios de

comunicación se

pueden clasificar

Reseña: Meros
Soldier throwing

flowers

copistas

El texto meros

copistas de

Lawrence Lessig

plantea la idea de

Alfabetismos

Mediáticos

Revista Royale es un

proyecto personal,

un medio digital en

Instagram que me

Comunidad

online

"Estaciondemusc

ulacion"

\section{Comunidad}

Online

IVHQ es una

comunidad donde

voluntarios de todo

el mundo viajan al

Medios de

comunicación

El medio caliente:

es aquel que

extiende en alta

definición un único

Medios fríos y

Medios calientes

Medio Frio: Tinder

Considero que

Tinder es una
The last supper

de Zeng Fanzhi

\section{(1)}

Hilda Palafox

(PONI)

Hilda Palafox, mejor

conocida como

"Poni", es una

artista visual

"The Work of Art

in the Age of

Mechanical

Reproduction"

Alfabetismo

mediático -

Comunidad

Online

(vegetarianos_ho

y)

Nuevos

alfabetismos

mediáticos $\mathrm{y}$

culturas

participativas

El grupo privado de

Facebook "¿Qué

materia me

recomiendan? -

Javeriana" es un

lugar en el que he

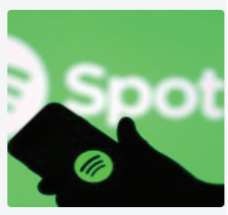

Comprend

er los

medios de

comunicac 


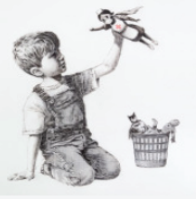

Venice in oil Bansky

Bansky es el pseudónimo de un artista de graffiti del que se desconoce

La obra de arte y la

reproductibilidad mecánica

Esta obra fue

creada por el

111 sou.4. $39.8 \mathrm{~m}$

mento $\&$.
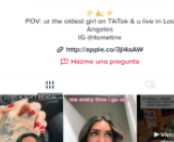

COMUNIDAD

ONLINE

TRIPADVISOR

En la comunidad

web de TripAdvisor

se suelen dar

\section{Comunidad}

online en

Facebook

El nombre de esta comunidad online

es Más Fit.

Medios Calientes:

La radio, porque

es un medio de

poca

participación y

en verdad uno

\section{Medios fríos y}

calientes

Por: Valentina

Rodríguez Skinner.

En primer lugar, una

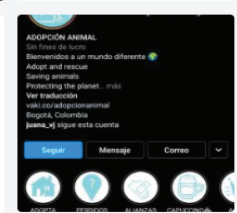

Este es un perfil en

TikTok, muestra a su

público ideas $y$

consejos sobre

marketing digital

que ayuden con

Una comunidad online

En este grupo de

Facebook, "Club del

libro"se ha

desarrollado un

Medios fríos y

calientes:

Por: Carlos Pinzón

Es clave entender

las características

\section{Comprender los}

medios de

comunicación:

Medios fríos y

calientes

Medios frios: Tik Tok

Comprender los

\section{medios de}

comunicación

(Las extensiones

del ser humano)-

medios calientes

Medios Fríos y

Calientes

Medio Caliente

Considero que

Spotify es un medio

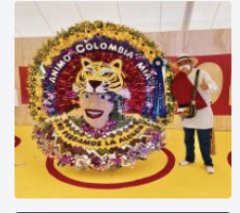

[Ò⿴囗十) Mural "El amor

no tiene género",

de Apitatán, en el

barrio Bellavista de

Quito, Ecuador.

2019

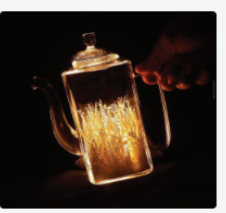

The Work of Art

in the Age of

Mechanical

Reproduction

Para mí una de las

obra de arte mas

Los nuevos

alfabetismos med

iáticos

Uno de los primeros

ejemplos que se me

vinieron a la cabeza

Comunidad

online Twitch

Twitch

Esta plataforma

emergente me

enseño que los

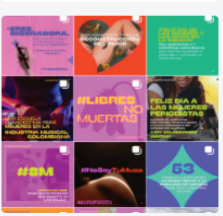

Comunidad

Online

La obra de arte y

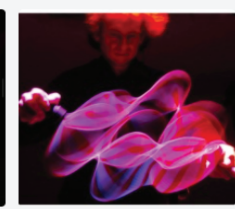

Medio caliente: el

cine. Es un medio

caliente ya que tiene

una gran densidad

de información, no

permite que haya

Medios calientes $y$ frios reproductibilidad

mecánica

Reseña Remix:

The Art and Craft

of Endless

Hybridization:

una propuesta de

alfabetización

\section{Alfabetismo}

Mediatico

Una liga Fnatasy

con personas que

solo conozco desde

ahi, y que consiste

Comunidad online

en instagram

Rinitips

Rinitips es una

iniciativa en la

WIKITEENS

\section{WikiTeens}

0.027250

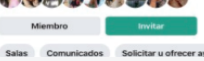

"The

\section{Prompt"-}

\section{Emma}

Krenzer

Graffiti - Zurik

El arte es un

concepto

sumamente amplio,

que permite una

variedad de

\section{Feminist -}

Instagram

Alfabetismo

mediático

Comunidad Body

Positive

IMBD

Medios frios $y$

calientes

Medios

Reseña

Gramophone,

film, typewriter

Medios fríos y

Medios calientes

y medios fríos

Medio Frío: para

este escogí la

app "Zello", cuya

función es servir

Figura 2. Visualización del archivo del blog colectivo versión 2021-1

Fuente: Reproducido del blog colectivo del curso Comunicación e Interactividad 2021-1 (https://comunicainter4ctive2021.tumblr.com/) 
Otro punto para la elección de Tumblr como infraestructura es que la plataforma ofrece varias posibilidades para modificar el aspecto de los blogs por medio del uso de plantillas prediseñadas y de la edición del código HTML y CSS. Como diseñador del blog colectivo asumí la tarea de crear la estructura del sitio web y modificar su aspecto visual. Este proceso fue iterativo. De este modo, el blog colectivo contó con las siguientes secciones: la página principal donde se muestran las entradas del blog en orden cronológico (primero aparecen las más recientes) y de forma dinámica (se actualiza con cada nueva publicación), y tres páginas estáticas: bibliografía, plan de estudios y presentación del blog (incluye descripción general y normas). Estas últimas tres páginas se acceden por medio de un menú que creé para tal fin y que aparece en la parte superior del sitio web.

En sus últimas dos versiones (2020-2 y 2021-1), el aspecto del blog es similar. En ambas iteraciones utilicé la plantilla "Iconic theme" creada por egg.design, la cual es de uso libre y gratuito, tiene una estética de tipo minimalista y una paleta de colores monocromática. A diferencia de las plantillas utilizadas en el 2019-2 y el 2020-1, este diseño facilita la identificación de los posts enmarcándolos dentro de líneas negras delgadas. Además, permite desplegar el archivo del blog de forma visual, lo que favorece la localización y el acceso a los contenidos ${ }^{7}$. Al desplegar el archivo se genera automáticamente una página web en donde se visualizan todas las entradas creadas por los participantes, organizadas en forma de cuadrícula y representadas por cajas en las que se incluye el título y una imagen pequeña. Cada caja funciona como un hipervínculo a uno de los posts realizados por los participantes. A medida que se realizan nuevas publicaciones en el blog, la cuadrícula se hace más extensa a fin de apreciar visualmente la diversidad de artefactos digitales y el crecimiento orgánico del portal durante el desarrollo del curso. En la figura 2 se puede apreciar esta funcionalidad y las posibilidades que ofrece para una fácil navegación, vista panorámica y acceso rápido a los contenidos publicados.

\section{RESULTADOS}

\section{Animando el portal: desafíos para estructurar la participación}

Como portal del espacio de afinidad de Comunicación e Interactividad, el blog colectivo fue diseñado e implementado como un lugar en la web para alojar y acceder a los contenidos del curso. Estos contenidos incluyen no solo contenidos académicos como la

7 Usualmente, el archivo de un blog se presenta en forma de texto, como una lista con los títulos o las fechas de publicación de las entradas, las cuales están enlazadas con hipervínculos a cada publicación. 
bibliografía y el plan de asignatura, sino también los contenidos generados por los estudiantes (posts) y la información general sobre el blog (presentación y normas). El portal puede entenderse como un repositorio vivo de contenidos, una especie de archivo dinámico y en expansión que todos los participantes consultan y construyen.

El blog colectivo crece orgánicamente a medida que los participantes publican nuevas entradas o posts. En el primer encuentro (presencial o telepresencial) de la clase que se realiza de forma sincrónica, luego de hacer una ronda de presentaciones de los participantes y de socializar el plan de asignatura (sílabo de la clase), el blog colectivo se introduce a los participantes como uno de los principales lugares para las actividades del curso. El docente proyecta el blog en el salón de clase o en las pantallas de los dispositivos conectados a videoconferencia y hace un recorrido por sus diferentes secciones. En ese momento, el blog no tiene ninguna entrada o post y los únicos contenidos publicados son los académicos y la sección de información general. El docente navega por estos contenidos, enfatizando su carácter público y abierto, y da ejemplos de cómo están conectados en red por medio de hipervínculos (por ejemplo, lecturas incluidas en la bibliografía). Además, se socializa la sección de información general del blog, subrayando que es un lugar público, construido por todos los participantes siguiendo unas normas básicas de participación y en donde todos los contenidos son publicados con licencias Creative Commons. Al finalizar esta presentación, se pregunta a los participantes si están de acuerdo con las normas del blog y si desean modificar o añadir alguna otra ${ }^{8}$.

A continuación, el docente lidera una actividad práctica y sincrónica en la que demuestra las funcionalidades de la plataforma Tumblr, explica cómo registrar una cuenta de usuario, da un ejemplo de creación (paso a paso) de un post y agrega a los estudiantes como colaboradores del blog. Al finalizar dicha actividad, la mayoría de los participantes habrán creado su primera entrada en el blog colectivo, la cual consistirá en un saludo y presentación informal. Este primer contenido multimodal (que incluye texto e imagen GIF), generado por los estudiantes, ayuda a ganar confianza y permite la expresión de identidades y el reconocimiento de la diversidad del grupo.

Participar en el blog colectivo se plantea desde el inicio como una de las actividades que permite alcanzar el propósito común del curso Comunicación e Interactividad. Además, la participación en el blog se valora también con un porcentaje $(5 \%)$ en la evaluación total del desempeño de cada estudiante. Para motivar y guiar la participación en el blog, el propósito compartido se refuerza con desafíos semanales que abordan las temáticas académicas del curso y plantean problemas que los estudiantes deben

8 En las cuatro iteraciones del curso, los estudiantes estuvieron de acuerdo con las normas sugeridas. Estas normas operan como una guía básica para participar y están planteadas de forma sencilla. 
resolver. Estos desafíos son generados por el docente y compartidos como anuncios en el portal Blackboard del curso enviados por correo electrónico a todos los participantes.

Tabla 2

Ejemplos de desafíos semanales. Datos del periodo 2021-1

\begin{tabular}{|c|c|c|c|}
\hline Semana & Tema & Desafío & Tipo de problema \\
\hline 3 & $\begin{array}{l}\text { Medios fríos } \\
\text { y calientes }\end{array}$ & $\begin{array}{l}\text { Realicen un post en nuestro blog colectivo que incluya } \\
\text { dos imágenes (estáticas o animadas) que hagan } \\
\text { alusión a dos tecnologías (medios) de comunicación } \\
\text { que ustedes hayan utilizado en algún momento de } \\
\text { su vida. Una debe ser de un medio frío y la otra de un } \\
\text { medio caliente. En el post, incluyan también un texto } \\
\text { en el que expliquen brevemente, en un párrafo, por } \\
\text { qué esas tecnologías son un medio caliente o frío. }\end{array}$ & Reflexión crítica \\
\hline 11 & $\begin{array}{l}\text { Cyborgs } \\
+ \text { bots }\end{array}$ & $\begin{array}{l}\text { Compartan una imagen de uno de los bots (o robots } \\
\text { sociales) con los que han tenido la oportunidad de } \\
\text { interactuar. En el texto que acompaña la imagen } \\
\text { respondan cuál es la identidad de ese bot, qué } \\
\text { características tiene y qué personalidad. }\end{array}$ & $\begin{array}{l}\text { Curaduría + reflexión } \\
\text { crítica }\end{array}$ \\
\hline 13 & $\begin{array}{l}\text { Gobernanza } \\
\text { de } \\
\text { comunidades } \\
\text { online }\end{array}$ & $\begin{array}{l}\text { Compartan una captura de pantalla de las normas, } \\
\text { guías o reglas de su comunidad online favorita. } \\
\text { Cuando hagan la captura identifiquen la norma o } \\
\text { regla que los usuarios o miembros de la comunidad } \\
\text { infringen más a menudo. Además, en un breve texto } \\
\text { den el ejemplo de un caso en el cual ustedes han } \\
\text { visto el incumplimiento de esa norma. }\end{array}$ & Indagación \\
\hline 15 & Memes & $\begin{array}{l}\text { Compartan una imagen de un nuevo meme que } \\
\text { ustedes creen y que esté vinculado a un tema de } \\
\text { actualidad colombiana, latinoamericana o mundial. } \\
\text { Tengan en cuenta que su nuevo meme debe tener } \\
\text { las características de humor e intertextualidad } \\
\text { identificadas por Knobel y Lankshear en el capítulo } \\
\text { "Online Memes, Affinities, and Cultural Production" } \\
\text { (2007). }\end{array}$ & Experimento \\
\hline
\end{tabular}

Elaboración propia

Como se observa en los ejemplos de la tabla 2, los retos son de diverso tipo y abordan diferentes temáticas. Algunos son problemas de autorreflexión, otros de indagación, otros de experimentación con medios y algunos otros de curaduría de contenidos. Independientemente de su tipo, todos los desafíos están diseñados para motivar el pensamiento crítico de los participantes, conectando las temáticas y lecturas académicas que se discuten cada semana con las experiencias, prácticas y conocimientos de los estudiantes. Además, los problemas son diseñados para apoyar la producción de 
artefactos digitales, abriendo oportunidades para que, por medio del hacer y la creación, los estudiantes conecten la teoría con la práctica.

\section{Multimodalidad y artefactos digitales}

El blog colectivo está centrado en la producción. Se ha estructurado principalmente para que los estudiantes produzcan artefactos digitales y los compartan fácilmente con todos los participantes del espacio de afinidad. Desde la primera sesión del curso, cuando los participantes tienen la oportunidad de interactuar sincrónicamente, se promueve la producción y publicación de productos multimodales en el blog colectivo. La interfaz y funcionalidades de Tumblr permiten que todos los estudiantes, independientemente de su experiencia y conocimientos, puedan publicar contenidos combinando múltiples lenguajes. Muestra de ello es la variedad de artefactos digitales creados por los participantes en su primera entrada del blog mezclando textos breves de saludo con animaciones GIF.

A medida que el curso transcurre, los participantes encuentran oportunidades para producir artefactos digitales resolviendo problemas relacionados con la temática abordada cada semana. Como se observa en la tabla 2, los desafíos que se comparten con los participantes incluyen indicaciones sobre los diferentes lenguajes (por ejemplo, escrito, imágenes estáticas y en movimiento) que pueden utilizarse en las publicaciones. Estas indicaciones se plantean para motivar a los participantes a diseñar artefactos digitales combinando múltiples lenguajes. El análisis de las publicaciones realizadas en las cuatro iteraciones del blog colectivo demuestra que la inclusión de este tipo de instrucciones en los problemas no solo incrementa el número de publicaciones semanales, sino también la riqueza semiótica y calidad argumentativa de los diseños multimodales ${ }^{9}$. Además, refleja que los ajustes realizados en los problemas o desafíos durante cada iteración han ayudado a mejorar los procesos de creación, indagación, experimentación y curaduría, así como la calidad de las composiciones multimodales, contribuyendo a la construcción de un espacio de afinidad. Por ejemplo, en la figura 3 pueden apreciarse las diferencias entre dos artefactos digitales generados para la temática "Gobernanza de comunidades en línea", uno del 2019-2 y otro del 2020-2.

9 El número de publicaciones semanales aumentó considerablemente con cada iteración del curso. Mientras que en la versión del periodo 2019-2 se realizaron 142 publicaciones, la del 2021-1 tuvo 340. 


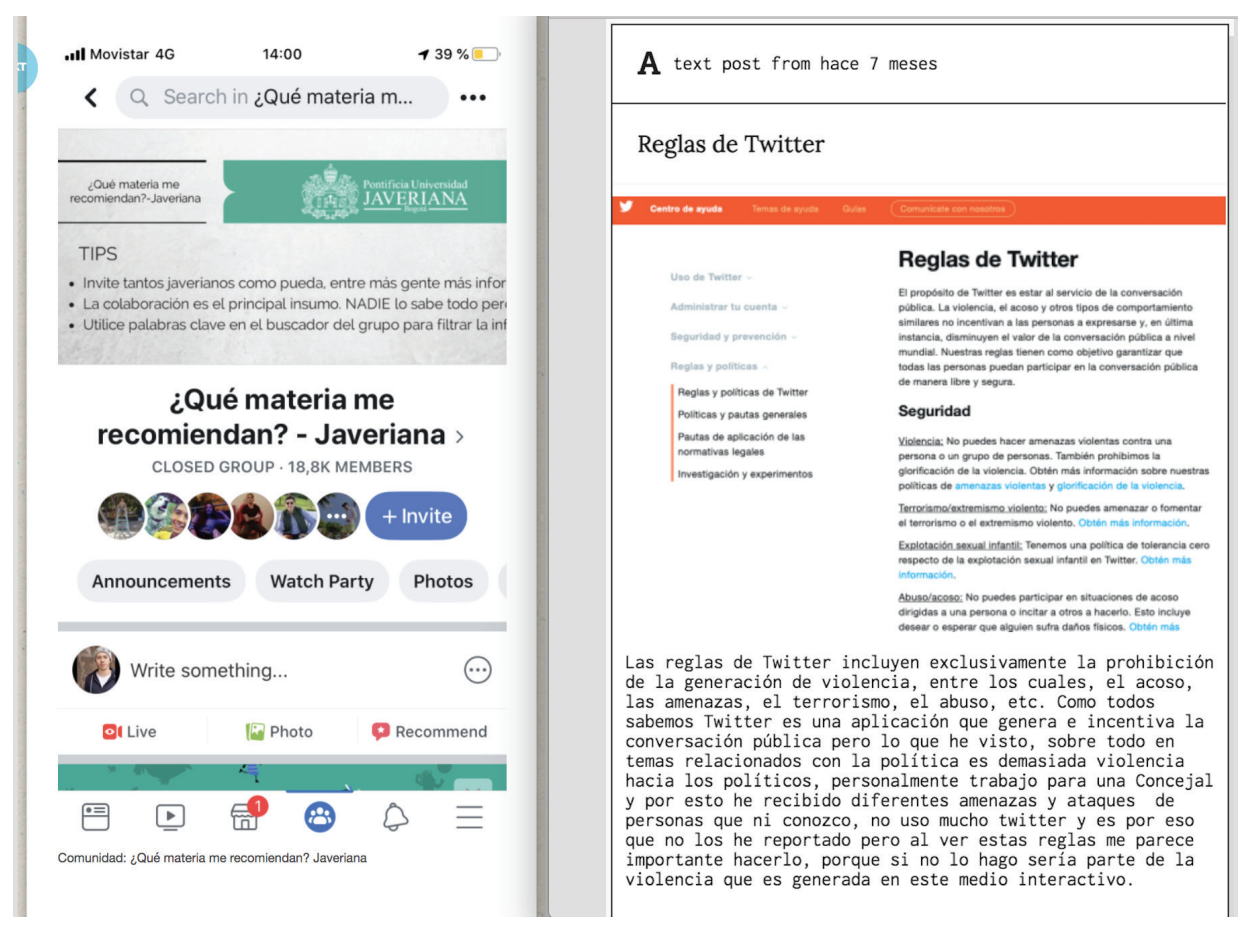

Figura 3. Artefactos digitales creados como respuesta al desafío "Gobernanza de comunidades en línea". Izquierda: post del 2019-2. Derecha: post del 2020-2.

Fuente: Reproducido del blog colectivo del curso Comunicación e Interactividad 2019-2 y 2020-2 (https://comunica-inter4ctive2021.tumblr.com/)

Mientras que el desafío del 2019-2 solo indicaba realizar la publicación utilizando únicamente una captura de pantalla de las normas o guías de la comunidad online favorita, el del 2020-1 incluía en las instrucciones identificar también la norma que los usuarios infringen más a menudo y un breve texto sobre un caso de infracción. La respuesta a los dos desafíos revela no solo una mayor elaboración en la composición del artefacto digital del 2020-2, en el que la imagen de las normas de Twitter es combinada con un breve texto argumentativo y crítico, sino también un proceso de reflexión y argumentación más alineado con el objetivo común del curso y el espacio de afinidad. 


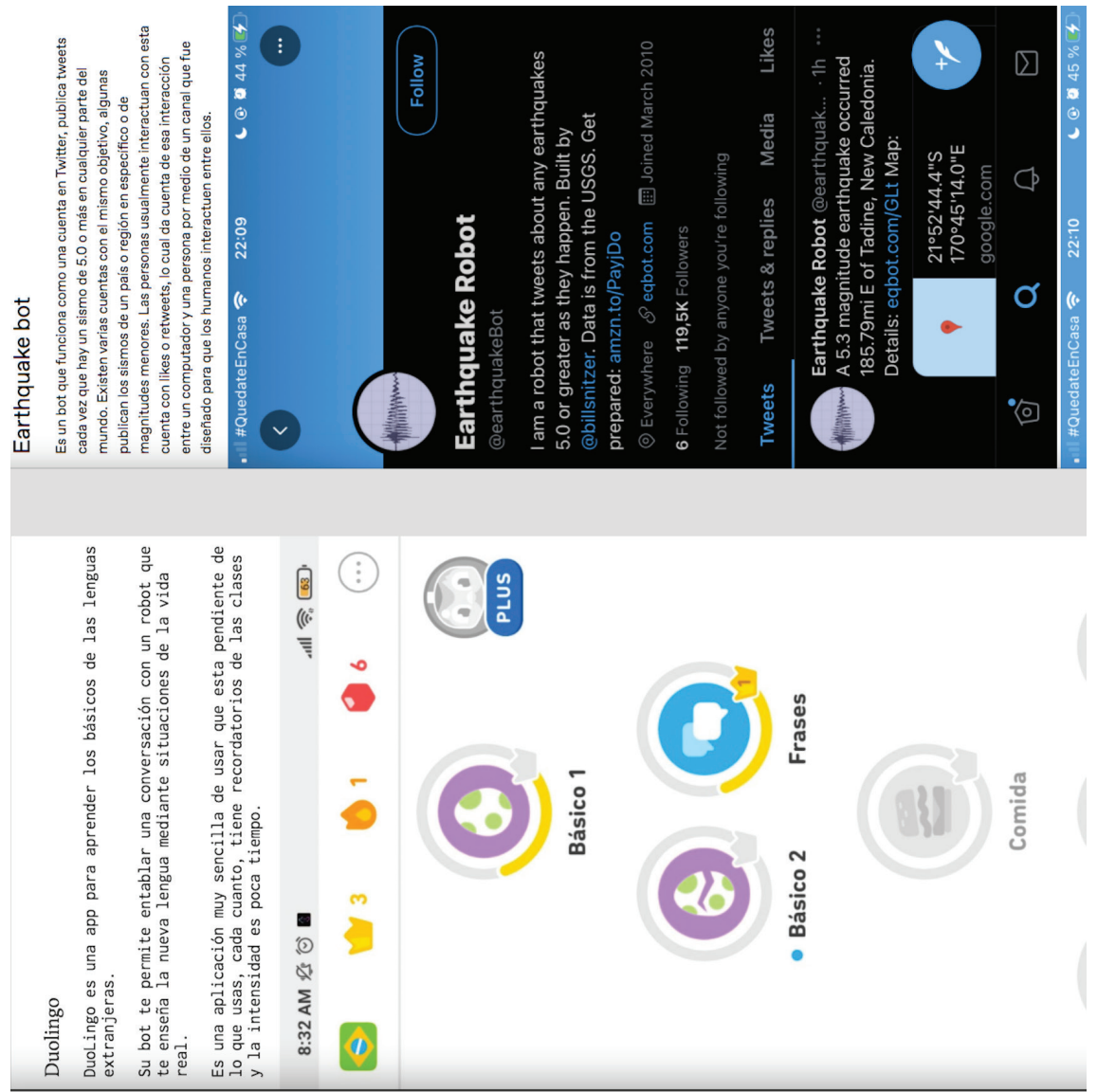

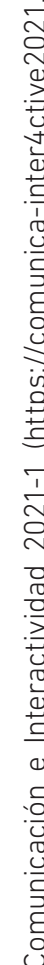

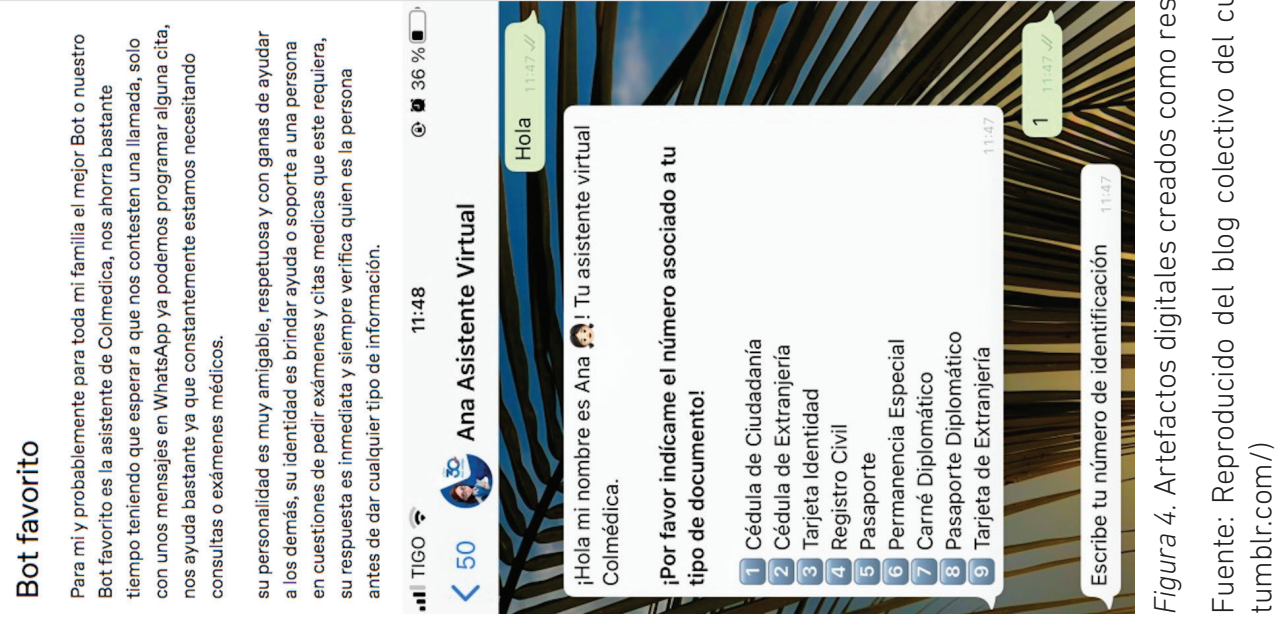


El análisis de los artefactos digitales publicados en el blog colectivo demuestra también que la mayoría de los participantes hace uso de sus dispositivos móviles para producir sus contenidos multimodales, combinando con destreza el lenguaje escrito y visual. Por ejemplo, la figura 4 muestra tres artefactos digitales que responden al desafío sobre la temática de "Cyborgs + bots", en los que es posible apreciar que el elemento visual es una captura de pantalla realizada desde un teléfono celular (nótense, por ejemplo, los indicadores de señal, hora y batería en la parte superior de la imagen). Para este desafío los estudiantes identifican uno de los robots sociales con los que han interactuado y reflexionan sobre sus características en términos de identidad y personalidad, conectando el contenido académico con sus experiencias y conocimientos mediáticos y de cultura popular.

El uso de este tipo de capturas de pantalla como recurso semiótico en los tres artefactos digitales provee evidencia sobre cómo la resolución de problemas y el hacer permite la conexión entre los intereses y saberes de los participantes (cultura mediática y popular) con los contenidos académicos del curso, en este caso, la temática de los robots sociales. La frecuencia de este tipo de material visual en los contenidos multimodales publicados en el blog colectivo indica también que muchos de los estudiantes utilizan la aplicación móvil de Tumblr en sus dispositivos móviles y que los teléfonos celulares facilitan el aprendizaje en cualquier lugar y momento.

\section{DISCUSIÓN}

Los resultados de este estudio de caso confirman el potencial del concepto de espacio de afinidad y del uso de la herramienta del blog colectivo para desarrollar el aula híbrida y fomentar el aprendizaje conectado. Por un lado, el espacio de afinidad permite estructurar una modalidad de aula en la que el aprendizaje y la enseñanza ocurren en múltiples lugares (físicos y virtuales) con la mediación de las TIC, y en el que se promueve la interacción y participación de todos los participantes. Adoptar este concepto permite al docente, a la manera de un arquitecto, estructurar las interacciones en el espacio de afinidad, creando rutas entre los diferentes lugares que lo componen y diseñando problemas o desafíos orientados a un propósito común. Este proceso de estructuración es innovador porque hace posible desarrollar un entorno social, interactivo y participativo, en donde el conocimiento está distribuido entre todos los participantes.

Sin embargo, la implementación y diseño de este tipo de espacio como parte de una clase universitaria presenta diferencias con su desarrollo en contextos de educación informal y culturas participativas en línea. En contraste con los espacios de afinidad teorizados por Gee, caracterizados por la fluidez y apertura, el espacio construido en el contexto universitario está atravesado por relaciones de poder, membresía a una comunidad y procesos característicos de la educación formal. Desarrollar este tipo de 
espacios en la academia requiere que tanto el docente como los estudiantes naveguen las relaciones institucionales con flexibilidad, fomentando la participación y las interacciones entre los participantes y reconociéndolas en la evaluación. El aprendizaje conectado ofrece estrategias útiles para navegar el contexto institucional por medio de la conexión de los intereses y prácticas de los estudiantes con los contenidos académicos y el énfasis en la producción de contenidos.

Por otro lado, el análisis del proceso de diseño e implementación del blog colectivo comprueba que esta herramienta, por sus características y posibilidades técnicas, es efectiva para desarrollar el aula híbrida en contextos como el colombiano, en el que la mayoría de personas se conecta a internet a través de teléfonos móviles. El uso del blog permite combinar presencialidad y virtualidad de manera fluida extendiendo el aula por medio de interacciones en línea, sincrónicas y asincrónicas, que no requieren conexiones a internet fijas o de banda ancha. Además, facilita el aprendizaje en cualquier lugar y momento, como lo revela la evidencia encontrada en algunos de los artefactos digitales publicados en el blog que incluyen capturas de pantalla realizadas con teléfonos celulares.

Los contenidos publicados por los estudiantes en el blog colectivo reflejan una pluralidad de voces, perspectivas, experiencias y conocimientos que enriquecen el espacio de afinidad y ayudan a alcanzar el objetivo común de la clase. Estos contenidos, en conjunto, ayudan a resolver los problemas planteados y a abordar las temáticas de la clase de forma colectiva. Por lo tanto, son esenciales para el diálogo que se adelanta en los encuentros sincrónicos presenciales y telepresenciales cuando las publicaciones son utilizadas como materiales para desarrollar la discusión, complementando el contenido de las lecturas académicas con ejemplos, reflexiones y experiencias de los estudiantes. Es precisamente en los encuentros sincrónicos donde la mayor parte de la retroalimentación sobre los artefactos digitales producidos por los participantes tiene lugar. Esta dinámica demuestra que el blog colectivo es una herramienta efectiva para apoyar el diálogo. La dinámica tradicional del seminario académico se expande, conectando la discusión oral a una red de contenidos y conocimientos generados por los participantes que pueden ser visualizados en las pantallas fácilmente.

Ahora bien, la aplicación de los principios del aprendizaje conectado ha posibilitado diseñar el blog colectivo como un portal centrado en la producción, conectado en red y con un propósito común. El énfasis en la producción, como principio de diseño del aprendizaje conectado, fomenta la creación de conocimiento y el desarrollo de nuevos alfabetismos a partir del hacer. Nuevos alfabetismos, como la remezcla y la navegación transmedia, son prácticas socioculturales que los jóvenes ya vienen desarrollando en su vida cotidiana a través del aprendizaje informal y sus interacciones con culturas participativas y mediáticas. Al centrarse en la producción, el blog colectivo reconoce estos aprendizajes y habilidades valorando los lenguajes, conocimientos y prácticas que los 
estudiantes utilizan en contextos diferentes al académico. La diversidad de artefactos digitales generados por los estudiantes demuestra que la conexión entre múltiples contextos (académico, hogar, culturas participativas y mediáticas), como principio del aprendizaje conectado, apoya el desarrollo de nuevos alfabetismos. Las publicaciones en el blog sobre las normas de comunidades en línea y sobre los robots sociales, tal como se ha analizado previamente, demuestran un proceso de reflexión crítica y composición multimodal en donde los estudiantes conectan sus experiencias y conocimientos mediáticos y de cultura popular con los contenidos académicos de la clase.

El estudio de caso contribuye a una mejor comprensión del proceso de construcción, diseño e implementación de un espacio de afinidad y de un blog colectivo para una clase universitaria. Las cuatro iteraciones del curso Comunicación e Interactividad permitieron tanto en las modalidades de educación presencial (2019-2), semipresencial (2020-1) y telepresencial (2020-2, 2021-1) desarrollar procesos de aprendizaje y enseñanza centrados en la producción y en la participación sincrónica y asincrónica de los estudiantes. Los cambios realizados en la apariencia del blog y en la forma en que se estructuró la participación en el espacio de afinidad impactaron positivamente no solo en el número de publicaciones en el blog colectivo (en el periodo 2021-1, el total de publicaciones fue más del doble que en el 2019-2), sino también en la calidad de los artefactos digitales en relación con su composición multimodal y reflexión crítica. Estos ajustes fueron aplicados al inicio de cada semestre con base en evidencias recolectadas durante el semestre anterior, tales como el desempeño de los estudiantes en las discusiones sincrónicas, la cantidad y calidad de los artefactos digitales generados en respuesta a los desafíos semanales, y la retroalimentación de los participantes. Además, los cambios fueron realizados en diálogo con investigaciones recientes sobre espacios de afinidad que han identificado estrategias efectivas para el fomento del aprendizaje conectado. Una de ellas es, precisamente, el diseño de problemas que motiven a los estudiantes a indagar, construir relaciones y producir artefactos digitales conectando sus intereses personales, la cultura popular y sus prácticas mediáticas con el contexto académico.

Docentes y educadores interesados en construir este tipo de espacios e implementar la herramienta del blog colectivo encontrarán en este caso estrategias y prácticas apropiadas para expandir el aula y facilitar el aprendizaje conectado. A manera de recomendación, se sugiere asumir una disposición exploratoria y experimental en la construcción de los espacios de afinidad, diseñando y estructurando los lugares, interacciones y contenidos de forma iterativa. Futuras investigaciones pueden evaluar el impacto del espacio de afinidad en los aprendizajes de los estudiantes por medio de instrumentos como entrevistas, grupos focales, encuestas o pruebas. Asimismo, vale la pena analizar en futuras investigaciones un corpus de artefactos digitales más extenso que permita indagar con mayor profundidad en la heterogeneidad de recursos semióticos utilizados y en el desarrollo de nuevos alfabetismos por parte de los participantes. 


\section{REFERENCIAS}

Acevedo-Rincón, J., y Flórez-Pabón, C. (2020). Virtual Education in the Colombian Context: Teaching Practices in Public and Private Education. Pesquisa e Ensino, Barreiras (BA), Brasil, 1(e202027), 1-21.

Asinsten, J. C. (2013). Aulas expandidas: la potenciación de la educación presencial. Revista de la Universidad de La Salle, 60, 97-113.

Black, R. W. (2005). Access and Affiliation: The Literacy and Composition Practices of English Language Learners in an Online Fanfiction Community. Journal of Adolescent \& Adult Literacy, 49(2), 118-128.

Boyd, P. (2013). Blogging in the Classroom: Using Technologies to Promote LearnerCentered Pedagogies. Researcher: An Interdisciplinary Journal, 26(3), 85-11.

Centro Nacional de Consultoría. (2020). Radiografía de la era digital en Colombia. https://www.centronacionaldeconsultoria.com/post/radiografia-de-la-era -digital-en-colombia-cnc-2020

Cheng, G., y Chau, J. (2011). A Comparative Study of Using Blogs and Wikis for Collaborative Knowledge Construction. International Journal of Instructional Media, 38(1), 71-78.

Cope, B., y Kalantzis, M. (2000). Introduction: Multiliteracies: The Beginnings of an Idea. En B. Cope y M. Kalantzis (Eds.), Multiliteracies: Literacy Learning and the Design of Social Futures (pp. 3-8). Routledge.

Curwood, J. S. (2013). The Hunger Games: Literature, Literacy, and Online Affinity Spaces. Language Arts, 90(6), 417-427.

Deng, L., y Yuen, A. H. (2011). Towards a Framework for Educational Affordances of Blogs. Computers \& Education, 56(2), 441-451. doi:10.1016/j.compedu.2010.09.005

Dewey, J. (1916). Democracy and Education. Macmillan.

Duart, J. M., Gil, M., Pujol, M., y Castaño, J. (2008). La universidad en la sociedad RED. UOC; Ariel.

Ferdig, R. E., y Trammell, K. D. (2004). Content Delivery in the 'Blogosphere'. THE Journal (Technological Horizons in Education), 31(7), 12-16.

Fook, J. (1999). Critical Reflectivity in Education and Practice. En B. Pease y J. Fook (Eds.), Transforming Social Work Practice: Postmodern Critical Perspectives (pp. 195-208). Allen and Unwin.

Freire, P. (1974). La educación como práctica de la libertad. Siglo XXI Editores. 
Galvis, A., Mariño, O., y Osorio, L. (2016). Innova-TE 330. Investigando la innovación con TIC en educación. Universidad de los Andes, Facultad de Educación; Centro de Innovación en Tecnología y Educación (Conecta-TE).

García, E., Elbeltagi, I., Brown, M., y Dungay, K. (2015). The Implications of a Connectivist Learning Blog Model and the Changing Role of Teaching and Learning. British Journal of Educational Technology, 46(4), 877-894. doi:10.1111/bjet.12184

García-Roca, A. (2016). Prácticas lectoras en espacios de afinidad: formas participativas en la cultura digital. Ocnos, 15(1), 42-51. doi:10.18239/ocnos_2016.15.1.979

Gee, J. P. (2003). What Video Games Have to Teach Us About Learning and Literacy. Palgrave Macmillan.

Gee, J. P. (2005). Semiotic Social Spaces and Affinity Spaces: From The Age of Mythology to Today's Schools. En D. Barton (Ed.), Beyond Communities of Practice: Language, Power and Social Context (pp. 214-232). Cambridge University Press. doi:10.1017/ CB09780511610554.012

Gee, J. P. (2007). Good Video Games and Good Learning: Collected Essays on Video Games, Learning and Literacy. Peter Lang.

Gee, J. P. (2015). The New Literacy Studies. En J. Rowsell y K. Pahl (Ed.), The Routledge Handbook of Literacy Studies. Routledge Handbooks Online. https://www. routledgehandbooks.com/doi/10.4324/9781315717647.ch2

Gee, J. P. (2017). Affinity Spaces and 21st Century Learning. Educational Technology, 57(2), 27-31.

González, S. (19 de agosto del 2019). Tumblr, la historia de una popular red social que ha terminado en el ostracismo. El País. https:/elpais.com/tecnologia/2019/08/15/ actualidad/1565860989_184909.html

Hall, H., y Davison, B. (2007). Social Software as Support in Hybrid Learning Environments: The Value of the Blog as a Tool for Reflective Learning and Peer Support. Library \& Information Science Research, 29(2), 163-187.

Ito, M., Arum, R., Conley, D., Gutiérrez, K., Kirshner, B., Livingstone, S., Michalchik, V., Penuel, B., Peppler, K., Pinkard, N., Rhodes, J., Salen, K., Schor, J., Sefton-Green, J., y Watkins S. C. (2020). The Connected Learning Research Network: Reflections on a Decade of Engaged Scholarship. Connected Learning Alliance.

Ito, M., Baumer, S., Bittanti, M., Boyd, D., Cody, R., Stephenson, B., Horst, H., Lange, P., Mahendran, D., Martínez, K., Pascoe, D., Robinson, L., Sims, C., y Tripp, L. (2010). Hanging Out, Messing Around, and Geeking Out: Kids Living and Learning with New Media. MIT Press. 
Ito, M., Gutiérrez, K., Livingstone, S., Penuel, B., Rhodes, J., Salen, K., Schor, J., SeftonGreen, J., y Watkins, S. C. (2013). Connected Learning: An Agenda for Research and Design. Digital Media and Learning Research Hub.

Ito, M., Martin, C., Cody, R., Rafalow, M., Salen, K., y Wortman, A. (2018). Affinity Online: How Connection and Shared Interest Fuel Learning. New York University Press.

Jenkins, H. (2009). Confronting the Challenges of Participatory Culture: Media Education for the 21st Century. MIT Press.

Kafai, Y. B., y Burke, Q. (2016). Connected Gaming: What Making Video Games can Teach Us about Learning and Literacy. The MIT Press.

Kress, G. (2010). Multimodality: A Social Semiotic Approach to Contemporary Communication. Routledge.

Kress, G., y Van Leeuwen, T. (2001). Multimodal Discourse: The Modes and Media of Contemporary Communication. Arnold.

Lammers, J., Curwood, J. S., y Magnifico, A. (2012). Toward an Affinity Space Methodology: Considerations for Literacy Research. English Teaching-Practice and Critique, 11, 44-58.

Lankshear, C., y Knobel, M. (2006). Digital Literacy and Digital Literacies: Policy, Pedagogy and Research Considerations for Education. Nordic Journal of Digital Literacy, 1(1), $12-24$.

Lankshear, C., y Knobel, M. (2007). Online Memes, Affinities, and Cultural Production. En M. Knobel y C. Lankshear (Ed.), A New Literacies Sampler (pp. 199-227). Peter Lang.

Lave, J., y Wenger, E. (1991). Situated Learning: Legitimate Peripheral Participation. Cambridge University Press.

Lugo, N., Melón, M. E., y Castillo M. C. (2017). La representación del autismo en las narrativas de fan fiction.net: los espacios de afinidad como oportunidad para la negociación de sentido. Palabra Clave, 20(4), 948-978. doi:10.5294/pacla.2017.20.4.5

Magnifico, A. M., Lammers, J. C., y Fields, D. A. (2018). Affinity Spaces, Literacies, and Classrooms: Tensions and Opportunities. Literacy, 52(3), 145-152.

Mejía Gallegos, C., Michalón, R., López, R., Palmero, D., y Sánchez, S. (2017). Espacios de aprendizaje híbridos. Hacia una educación del futuro en la Universidad de Guayaquil. MediSur, 15(3), 350-355. https://www.redalyc.org/ pdf/1800/180051460010.pdf

Ministerio de Tecnologías de la Información y las Comunicaciones. (abril, 2020). Acceso móvil a internet. En Boletín Trimestral de las TIC. Cifras Cuarto Trimestre del 2019 
(pp. 19-33). https://colombiatic.mintic.gov.co/679/articles-135691_archivo_ pdf.pdf

Mortari, L. (2015). Reflectivity in Research Practice: An Overview of Different Perspectives. International Journal of Qualitative Methods, 14(5), 1-9. https://journals.sagepub. com/doi/pdf/10.1177/1609406915618045

Nackerud, S., y Scaletta, K. (2008). Blogging in the Academy. New Directions for Student Services, 2008(124), 71-87. doi:10.1002/ss.296

Osorio, L. A. (2010). Características de los ambientes híbridos de aprendizaje: estudio de caso de un programa de posgrado de la Universidad de los Andes. Revista de Universidad y Sociedad del Conocimiento (RUSC), 7(1), 1-9.

Scolari, C. A. (2016). Alfabetismo transmedia. Estrategias de aprendizaje informal y competencias mediáticas en la nueva ecología de la comunicación. Telos: Cuadernos de Comunicación e Innovación, 103, 12-23.

Sim, J. S., y Hew, K. F. (2010). Review: The Use of Weblogs in Higher Education Settings: A Review of Empirical Research. Educational Research Review, 5(2), 151-163. doi:10.1016/j.edurev.2010.01.001

Stephens, M. (2016). Connected Learning: Evaluating and Refining an Academic Community Blogging Platform. Journal of Education for Library and Information Science, 57(4), 295-310.

Vygotsky, L. S. (1978). Mind in Society: the Development of Higher Psychological Processes. Harvard University Press.

Wang, Y., Lin, H., y Liao, Y. (2012). Investigating the Individual Difference Antecedents of Perceived Enjoyment in Students' Use of Blogging. British Journal of Educational Technology, 43(1), 139-152. doi:10.1111/j.1467-8535.2010.01151.x

Wenger, E. (1998). Communities of Practice: Learning, Meaning and Identity. Cambridge University Press.

Xie, Y., Ke, F., y Sharma, P. (2008). The Effect of Peer Feedback for Blogging on College Students' Reflective Learning Processes. Internet and Higher Education, 11(1), 18-25. 